\title{
Psychological Empowerment on Organizational Commitment as Perceived by Saudi Academics
}

\author{
Nouf Bin Jomah ${ }^{1, *}$ \\ ${ }^{1}$ Department of educational administration, Education College at King Saud University, B.O BOX 21332, Riyadh, \\ Saudi Arabia \\ *Correpondence: Department of educational administration, Education College at King Saud University, B.O BOX \\ 21332, Riyadh, Saudi Arabia. Tel: 966-114-674-945. E-mail: nouf_5@hotmail.com
}

Received: December 20, 2016

Accepted: January 17, 2017 Online Published: February 17, 2017

doi:10.5430/wje.v7n1p83

URL: http://dx.doi.org/10.5430/wje.v7n1p83

\begin{abstract}
Various scholars have identified commitment as one of the major contributors of workplace productivity. Commitment provides the interest and morale for handling tasks which results in organisation progress and growth. Commitment is perceived as either continuance, normative, or continuance commitment. The three commitment categories are fundamental, and academics have established empowerment as a fundamental tool for developing workplace commitment. Significantly, empowerment is categorized as either psychological or structural. Psychological empowerment is purported to increase the commitment levels in institutions. Basically, psychological empowerment is concerned more with personnel experience and their responsibilities in the organization rather than focusing on managerial activities. This study, therefore, establishes the validity of psychological empowerment in improving the commitment levels among institutions.

The study sampled 100 employees from varied departments in King Saudi University. The participants were distributed in accordance with their working experience; twenty of the respondents had worked for between 11 and 15 years, thirty had a working experience of 6-10 years, and the majority (50) had worked for less than five years. The level of psychological empowerment (PE) and the corresponding organization commitment (OC) was measured through a survey questionnaire. In both questionnaires, the items were measured in 7-point Likert- type, with the least value being 1 (strongly disagree) and the highest 7 (strongly agree). The results of the study indicated that that the average of psychological empowerment and the five dimensions relating to it with organization commitment were on the higher side. Notably, organization commitment relied heavily on the level of autonomy given to the employee in decision making at the workplace.
\end{abstract}

Keywords: psychological empowerment; organizational commitment; saudi aademics

\section{Introduction}

\subsection{Background Information}

Individuals within institutions are the primary factor for survival in an environment that is highly competitive and also a major part in the productivity of the institution. Though within most institutions, personnel have reported feeling undervalued, isolated, exploited and dehumanized. With regard to these factors, one of the relevant techniques to improve the productivity of staff and the best use of capabilities and capacities of groups and individuals in line with institutional goals isempowerment. Human resource empowerment is the new boost for a booming and growingworkplace.Theproductivityof creativity and human capital energy are an institution's most relevant resource. In order to be successful in the current competitiveenvironment, organizations requirecreativity, energy, knowledge and ideas of every human resource, directly from front line personnel upto the high-ranking managers among the executive (Ambad, 2012).

Empowerment means enabling individuals to exercise power or granting them power. It consists of two concepts, which are psychological and structural empowerment, the earlier being the focus of the research.The empowering of personnel and developing OC among them is regarded as taking a long way in showing how different an organization is from the others. On the other hand, individual's involvement and identification with an organization is known as 
organizational commitment.

The independent variables of the study were meaning, competence, self-determination, and impact whereas OC was the dependent variable. The moderating variables entailed length of service and level of education. All of the dimensions were to identify how they are related to organizational commitment.Brought out by the research is that what influence the organizational behavior of workforce are their reactions to conditions set by the management and not the condition of the context of work.

The results showed that it is though psychological empowerment that employees develop commitment for their work. Indicated by the research is that giving opportunity, freedom and autonomy generate a sense of empowerment in employees and thereby, work towards sustaining the institution by employing their best efforts and developing more commitment to their work. Additionally, the work force generates more commitment to their employer when they take part decision making process and in the outcomes affecting the organization (Ambad, 2012). It is considered that OCis a key determinant of institutional outcomes like organizational citizenship behavior, absenteeism, controllability and performance (Snape and Redman, 2003). The study tries to provide answers to the questions: "To what extent do the demographic traits of employees like length of service and level of education provide a moderation between organizational commitment and psychological empowerment?" and"Does there exist any kind of relationship between the components of organizational commitment (OC) and the dimensions of Psychological Empowerment (PE)?"Answers to these questions identified in other research work and literature are reduced levels of turnover, improved commitment to work, organizational citizenship behavior, improved effectiveness, greater job satisfaction and stronger motivation to work.

\subsection{Hypotheses}

The hypotheses of this study are:

1a Continuance commitment is influenced by psychological empowerment

$1 \mathrm{~b}$ Normative commitment is influenced by psychological empowerment

1c Affective commitment is influenced by psychological empowerment

\subsection{Saudi Higher Education}

Over the past decade, the Saudi Arabia Higher education has noted a tremendous development. The Saudi higher education system is based on diversification, and it has expanded to entail:

$\begin{array}{ll}\checkmark & 18 \text { Men-based Primary teacher's colleges } \\ \checkmark & 80 \text { Women-based Primary Teachers Colleges } \\ \checkmark & 37 \text { Health institutions and colleges } \\ \checkmark & 12 \text { Technical colleges } \\ \checkmark & 33 \text { private universities } \\ \checkmark & 27 \text { Private colleges (Alamri, 2011). }\end{array}$

Though the private institutions that provide higher education started operating more recently, their numbers have increased over the few years and still have a positive trend. The year 2005 marked the launching of "King Abdullah Scholarship Program" by the ministry of higher education. Fulfilling the requirements of job markets in the nation and solving the issue of faculty members in higher education organizations were the primary aims of establishing the program. As indicated by a report published on the website operated by the Ministry of Higher Education in Saudi Arabia, UNISCO ranked the country fourth with regard to the number of scholars from the country moving around the world to seek higher education (Alamri, 2011). On the other hand, the Saudi ministry of higher education began providing sponsorships to students in 2010 to students admitted to private universities. The move was to give a chance to students who are unable to afford tuition and fees needed by the local varsities.

Bureaucracy proves to be a critical in Saudi Arabia's higher education even given that most of Saudi's deans of schools were educated internationally. For example, the education system is centralized in the Higher Education ministry and in that case, there is a lack of clear avenues that allow changes that could trigger a milestone move towards improvement. There is no motivation system for the expatriate faculty even when there is a high percentage of the faculty. Furthermore, they are discriminated in terms of incentives and salaries. A study by Alamri (2011) shows that non-Saudi faculty members are paid lesser than the Saudi faculty members. Besides, the Saudi Arabia faculty members are paid incentives such as publications incentives, which are mostly denied to non-Saudi faculty members. 


\section{Literature Review}

\subsection{Organizational Commitment}

Employees'commitment to an organization can be defined as the representation of desire and loyalty that employees possess with regard to their involvement in the organization (lambert, 2004). Previous researchers indicated that high levels of commitment to an organization could be associated with reduced levels of turnover rates and absenteeism. Most of the studies made an attempt of identifying the link between work behavior such as turnover and organizational commitment (Chen \& Francesco, 2003) and the intentions of work force to resign (Dee, Henkin \& Duemer, 2002; Snape \& Redman, 2003; Gautam, Van \& Wagner, 2001; Bozeman \& Perrewe, 2001).

Research by Dee, Henkin and Duemer (2002) that was conducted on teachers in eight elementary schools located in South-Western U.S in an urban claimed that organizational commitment and psychological empowerment are positively related. Their findings also indicated that the human resource has the power or right of making decisions regarding the daily management of the institutions, their organizational commitment will rejuvenate. Moreover, the three scholars deducted that the only aspect that lacks a significant relationship with organizational commitment is competence cognition. Another research, whose findings were somehow different was one carried out by Nabila (2008) founded that impact and competent dimensions bear a significant relationship whereas self-determination and meaning cognitions lack a significant relationship.

The level of employee commitment is a crucial tool for predicting whether an employee will leave an organization soon or is willing to stay longer. That is because a lower level of employee commitment indicates a sooner resignation. A feeling of job empowerment has been suggested by past studies to be a facilitator of commitment by workers in an organization.Spreitzer (2007) asserted that more than $70 \%$ of institutions globally have embraced and implemented the idea of practicing some sort of empowerment on their employees.

Job commitment, which is a second variable of the research, was studied by scholars like Dewettinck (2003), Dee et al. (2003), Laschinger et al. (2001) and Liden et al. (2001). All ther studies showed that not all of the dimensions of PE portray a positive relationship with certain variables. Like most of the other researchers, they nodded to the argument that the commitment of management staff is raised by psychological empowerment; though, it had negative effects on the non-management employees due to less awareness about the authority system and inadequate training. In such a situation empowerment to non-management employees will lead to an increase of job stress, reduced morale and eventually, reduced commitment. Also, the majority of previous studies show that organizational commitment and self-determination cognition lacks a significant relationship.

Research conducted by Somech and Bogler (2004) conducted in Israeli high and middle schools examined relationships between the professional and organizational commitment of teachers with empowerment. They also studied organizational citizenship behavior and like most of other related studies, they concluded that the teachers' level of empowerment and feelings of commitment were significantly related to their profession and institution.

Impact cognition depicted the most occurring outcomes from previous studies in comparison to the other cognitions of PE. Concerning impact cognition, bosses empower their workers by providing them withautonomy and opportunity to come up with decisions about their job methods, efforts, and pace in order to improve the commitment of subordinates (Nabila, 2008). In case the superiorsallow their workers to participate in the process of decision making, affective commitment to the institution among the employees will be stronger. Institutions that practice decentralization and not centralization by distributing power to their human resource to come up with certain decisions will generate a higher affective commitment among the workers (Choong, Wong \& Lau, 2011). Personnel who are empowered psychologically by superiors tend to develop a more affective attachment to the organization and also feel more obligated to stay and continue working for the organization. It indicates that affective commitment is highlyassociated withPE.

It can be deducted that according to most of the previous studies, there is a negative relationship which exists between $\mathrm{PE}$ and continuance commitment. It is not a must that continuance commitment should be the beneficially attitude of an organization. Though human resource might be willing to work longer with the organization, it might be due to not being able to find a job that is more financially rewarding than the current one. In such a case, the employees are hesitant of resigning because they will lose more than gain by so doing.

\subsection{Psychological Empowerment}

A psychological perspective focuses more on how personnel experiences their responsibilities in the organization rather than focusing on managerial activities which distribute power to all human resourceat all ranks. This perspective, therefore, implies that the personal belief that human resource has regarding the organization they are employed in is 
directly linked to employee empowerment (Spreitzer, 2007). Asiah (2006) discussedvarious types of structures, concepts and meanings of PE, which have been derived and explored from previous practitioners' researches and past scholars like Menon (2001) who defined empowerment as a state of psychology that is manifested in goal, competence and control and Konczak et.al (2000) who referred to empowerment as a positive behavior by a superior to the juniors. Studies by Dewettinck et al. (2003), Holdsworth and Cartwright (2003) Laschinger et al. (2002), Savery and Luks (2001), Liden et al. (2000), Davis and Wilson (2000) discovered that there is a positive relationship between PE and job satisfaction.

Liden and colleague researchers (2000) argued that among the four dimensions of empowerment, meaningfulness was the robust theoretical argument pertaining to a positive relationship with regard to satisfaction at work. They explained that actions by management that elicit empowerment on employees are the provision of chances to the work force to vent out their personal suggestions and opinions, creating opportunities for employees to come up with decisions, assigning employees tasks that are of more importance to the organization and giving the workers more responsibilities. When human resource believes that they are always executing the orders from their leaders as opposed to their own actions that they deem relevant, they will feel denied freedom and autonomy and thereby, they will tend to feel less empowered.

These studies indicate that psychological empowerment can evoke organizational commitment sincehaving impact enablesemployees' possibilities in participating in shaping an institution's system that they are attached to. Self-determination provides workers with a voice in work-related decision processes and with enhanced control over their job; hence, leading to the increased involvement in the institution's operations.Self-determination can exist when personnel has little control over a number of efforts they will deploy in executing their tasks and what they will do. The dimensions of self-determination dimension are very important in enhancing academicians' OC (Choong, Wong \& Lau, 2011). Employees and in this case, academic staffs should enjoy the freedom of planning and organizing their daily job.

Senses of competence enableemployeestobelieve that that they are capable of performing their job roles with success and skills, and in turn encouraging them to put considerable efforts on while working for the organization.For a job to be considered meaningful, it must provide a suitable line between the essentials and purposes of a person's organizational job roles and his or her personal value attributes. Considering competence and meaning cognitions, it is explained that both are critically related to OC. The management of organizations has to ensure that the goals of the assigned work task correspond to their workforce's value attributes so that they perceive the task as relevant.

\subsection{Some Studies in Impact of Psychological Empowerment on Organizational Commitment in Higher Education}

A study by Chan (2003) provides that there exists a negative and not a positive relationship between PE and continuance. The researcher interpreted this to imply that if the human resource experiencea higher level of psychological empowerment, theyusually becomeunlikely to gain motivation from continuance commitment in order to remain working for the organization. Personnel that depict a high continuance commitment may choose to stay in the organization, an aspect that they cognitively assess that they are willing tobut not because they want to stay because of theneed to relocate or pension plans (Chan, 2003).

Chan (2003) also noted that there exists a direct relationship between psychological empowerment and normative commitment. That may be because personnel hat are psychological empowered depict an emotional attachment to the organization.Chan (2003) also asserts that employees who haveahigh PEalso depict a high normative commitment for the institutions they work for. His hypothesis was pillaredby other studies that posited that there is a positive and direct relationship between normative commitment and psychological empowerment. The Higher commitment will subsequently result inlower absenteeism and higher employees' retention. In turn, the employees can make more positive contributions towards the organizational effectiveness (Choong, Wong \& Lau, 2011). The successful shaping of the attitudes of the academic staff can eventually lead to enhancement of overall organizational performance, productivity, innovation, and creativity.Eventually, thatwill enable them to generate competitive and higher quality graduates to support the country's economic growth.

\section{Methodology}

\subsection{Sample}

One hundred working employees working in different departments at the King Saud University made up the team of respondents and to they included forty female and sixty male respondents. With regard to work experience, twenty of the respondents had worked for between 11 and 15 years, thirty had a working experience of 6-10 years, and the 
majority (50) had worked for less than five years.

\subsection{Instruments Used}

\subsubsection{Psychological Empowerment}

The popular scale of Mishra and Preitzer wasa used to measure psychological empowerment. The questionnaire comprised of fifteen items that were grouped into five PE dimensions that included condense, impact, self-determination, competence and meaningfulness. Meaningfulness implies the value of job objective that is judged in connection with a person's own standards and ideals. Individuals' beliefs that they can well in tasks assigned to them is referred to as competence. A person's feeling of bearing an opinion in starting and regulating the procedures of work is associated with self-determination. An impact refers to the feeling that an individual have if he or she has an influence on the outcomes of tasks. The aspect of an individual being fairly behaved is regarded as condense (Konczak et al., 200). It is assumed that psychologically empowered employees do not have a passive orientation towards their job roles but rather, they have a proactive orientation. Also, they are assumed to have a feeling of increased intrinsic job motivation. A workforce that is committed and empowered is considered essential for the effective running of modern organizations.

\subsubsection{Organizational Commitment}

To measure OC, a brief version of the Meyer and Allen's organizational commitment questionnaire (22) was used. Changing and shapping the staffs' attitudes areparamount in enhancing workers' organizational commitment to ensure an overall improvement of the performance of an organization. So that the teaching quality is maintained and to enable a successful competition in both domestic and international education ranks, it is critical for administrators at King SaudUniversity to understand the attitudes and behavior of its academic staffs. By having such an insight, heads and deans of departments would be able to shape the attitudes pertaining to the academics by implementing empowerment that will in turn result inahigher organizational commitment. Organizational commitment refers to an employee's identification with an organization and also his or her involvement in it. It is characterized by a strong belief and the acceptance of the goals of the organization and values alongside the willingness to exert a considerable determination and commitment on behalf of an institution. Proposed by previous scholars were three components of commitment that include normative, affective, and continuance commitment (Rawat 2011). Affective commitment means an employee's involvement in an organization, identification with and emotional attachment to an organization. Normative commitment implies an individual's feeling of obligation, which pressesone to remain working for the organization and not think of working for any other organization even if they offer a better compensation. On the other hand, continuance commitment means the awareness of the costs incurred when one resigns from an organization, the need for employees to continue working for the institution because of they no other choice.

\subsubsection{Scale}

In both the questionnaires, the items were measured in 7-point Likert- type, with the least value being 1 (strongly disagree) and the highest 7 (strongly agree). Regarding psychological empowerment (PE), the total score ranges between $15-105$ and from 5 to 35 for Organizational Commitment (OC).

\subsection{Validity and Reliability}

To enable using the questionnaires in a Saudi context, they had to be translated into Persian. In order to ensure that the wordings of statements in the questionnaire were simplified and to ascertain its consensual validity, the skills of three experts in the field was used to inspect the Persian version. Thirty respondents were enrolled and then excluded from the main study, but their comments were used to make the final adjustments. The reason for their enrolment was to conduct a pilot study. The calculation of Cronbach's alpha was done to measure the internal consistency reliability pertaining to the questionnaires. A reliability of 0.864 for OC measured. On the other hand, for PE a reliability of 0.901 was measured, and that entailed 0.821 impacts, 0.901 confidence, 0.903 self-determination, 0.781 competence and 0.853 meaning.

\section{Data Analysis}

Standard deviation and mean (descriptive statistics) were incorporated in the summarization of the data. Simple and multiple regression analyses, Pearson's correlation analysis and one-sample t-test, were put in practice to analyse the data.To compare the supposed mean with the sample mean, the one-sample t-test was used. OC was considered as the dependent variable while the PE together with its five dimensions was regarded as independent variables. To measure the relationship strength between $\mathrm{OC}$ and PE with its dimensions, a calculation of the Pearson's correlation 
coefficient was done. The study opted to examine an extent to which psychological empowerment can predict Organizational Commitment and to ensure that a simple linear regression was carried out. Stepwise multiple regression analysis was employed to ascertain the extent to which each dimension of OC would have an effect on PE.SPSS Version 16 Software was used to carry out all statistical analyses and $\mathrm{P}<0.05$ was perceived as significant statistically.

\subsection{Survey Findings}

Table 1. Descriptive Statistics of the Perceived PE and Its Dimensions and OC, and the Results of T-Test for Comparison of the Variables with the Average Values

\begin{tabular}{lllllll}
\hline Variables & Min & Max & Mean & SD & t & Significance \\
\hline Psychological Empowerment (PE) & 20 & 101 & 75.80 & 22.08 & 4.283 & $<0.001$ \\
Meaning & 4 & 22 & 14.44 & 6.18 & 7.182 & $<0.001$ \\
Competence & 4 & 22 & 18.38 & 15.48 & 13.791 & $<0.001$ \\
Self-determination & 4 & 22 & 13.09 & 5.09 & 5.881 & $<0.001$ \\
Impact & 4 & 22 & 14.80 & 5.88 & 4.461 & $<0.001$ \\
Confidence & 4 & 22 & 14.77 & 6.98 & 2.986 & $<0.04$ \\
Organizational Commitment (OC) & 6 & 22 & 24.93 & 7.99 & 4.982 & $<0.001$ \\
\hline
\end{tabular}

The table depicts that the average of PE and the five dimensions relating to it with $\mathrm{OC}$ were on the higher side. The results reflect that length of service and level of education does not really moderate the relationship between OC and PE. As already mentioned and depicted by the table, OC will increase when employees are provided with the autonomy for decision making concerning the process of work. Human resource gives their commitment to the institution they are employed to when they feel supported and secured by the institution and also when they develop confidence that their contributions are effectively rated by the management. Many of the earlier studies asserted that the length of employees' service could be used as a tool for estimating their levels of job satisfaction. That also leads to the assumption that the most satisfied employees tend to remain working for long while the less satisfied ones tend to terminate their services with the organization the work for.

Table 2. Correlations of Psychological Empowerment and its Dimensions with Organizational Commitment

\begin{tabular}{llllllll}
\hline & PE & ME & CO & SD & IM & CN & OC \\
\hline PE & 1 & & & & & & \\
ME & 0.824 & 1 & & & & & \\
CO & 0.688 & 0.5 .893 & 1 & & & & \\
SD & 0.852 & 0.621 & 0.532 & 1 & & & \\
IM & 0.872 & 0.661 & 0.592 & 0.582 & 1 & & 1 \\
CN & 0.862 & 0.681 & 0.572 & 0.592 & 0.692 & 1 & \\
OC & 0.852 & 0.671 & 0.542 & 0.572 & 0.672 & 0.642 & 1 \\
\hline
\end{tabular}

Internal correlation of the research variables has been provided in the table. Observed were the lowest and highest correlations with organizational commitment with regard to meaning and competence dimensions respectively. The simple regression results indicate that there is a positive impact of workers' empowerment on their organizational commitment.

As observed, there existed crucial positive correlations between organizational commitment and psychological empowerment together with PE dimensions. Therefore, it can be precisely assessed in a regression model. Multiple and simple regression were applied between independent and dependent variables to further investigate the preliminary findings. Hence, PE was an important predictor of OC. To ascertain the role of the five dimensions of PE in the prediction of OC, the study applied the stepwise multiple regressions and the results presented in table II above. The table indicates that confidence, self-determination, and meaning, which are among the five dimensions of PE,are 
crucial predictors of commitment. When all the three dimensions are entered together in the model, they provide an explanation to the variance in commitment. When studying how the sub dimensions of empowerment impact commitment dimensions, it can be deducted that all the factors together did not influence normative commitment but they did have an influence on the affective and continuance commitment. Due to the fact that psychological empowerment results in a feeling of being enabled directly from within as a result of management practices, and culture, it strengthens continuance commitment. It can also be deduced from the table that empowerment provides employees with the power of making decisions.

Meaningfulness portrays a significant relationship with normative and affective commitment. Meaningful work is that which provides a suitable fit between purposes and requirements of an individual's personal value system and organizational work roles. Also, self-determination was related in a significant way with continuance and affective commitment. To reiterate, self-determination enables an enhanced involvement of employees in an organization because it gives employees a voice in job-related decision processes and control over their job. Competence can also be linked to the continuance commitment. A sense of competence stimulates employees to exert considerable efforts on behalf of the institution and also motivates them to develop self-belief that they can carry out their duties successfully and skilfully (Rawat, 2011).

\section{Discussion}

Employees who are empowered proactively execute their responsibilities, and that is the reason why they are likely to be seen as effective. Such employees view themselves as able and competent enough to have an influence on their work environments as well as on their jobs in a meaningful way (Dewettinck et al., 2003). The empowerment experience is established in four dimensions in that in case any of the dimensions is missing; then there will be a limited experience of empowerment. If employees lack a sense of competence like when they doubt their abilities and skills to perform a certain task even though they are eager to make an impact, they will not have the feeling of empowerment. On the other hand, if individuals have self-determination (the discretion of making decisions) but lack a sense of meaning (they care less about the types of decisions they can possibly make), they will feel a lack of empowerment (Spreitzer, 2007).

Impact and self-determination are the two PE dimensions that positively relate to organizational commitment. The respondents of the study nodded to the fact that when they are given the autonomy of making decisions concerning their efforts, pace, and work methods, their organizational commitment will definitely increase. They added that if they believe that they can have an influence on operation, administrative or strategic outcomes, they can commit their loyalties to the organization.Also approved by the respondents was that their organizational commitment are likely to improve if the types of tasks they are assigned inherently entail particular intrinsically motivating traits, feedback, task significance and remarkable varieties of skills.As already discussed, not all the four psychological empowerment cognitions are positively related to organizational commitment, but generally, psychological empowerment may be a crucial means or element for increasing the organizational commitment of employees, thereby, reducing absenteeism and burnout (Dee, Henkin \& Duemer., 2002).

Competence and meaning are the other two dimensions of psychological empowerment that lacks a positive relationship with organizational commitment. Regarding competence, even if employees have the confidence that they have the abilities to perform a certain task, there is no guarantee that they are committed towards their organization. That is to mean that even though organizational and employee's values may be similar, it is not enough for them to pledge their loyalty to the institution they work for. The management of an organization can aid in building an organization culture and atmosphere that enable open communication. With the existence of an open communication working environment feedback is encouraged, questioning is supported, individual's opinions are taken into account and personnel are free to air their personal views. Feedback may increase employee empowerment in aspects like confidence dimensions, impact and self-determination.

The concept of Human Resource Management is a critical subject that requires a clear understanding of the environment in which labour is based. An intellectual environment have an effect on hiring of labour in that skills requirements and academic set credentials pertaining to a job must be achieved so that hiring of Human Resource can be possible. Reward and the incentive is important to both the employers and the employees. Employees will always be willing to work properly and produce good results if they feel appreciated. Rewards provide a sense of self-worth to the employees. They feel good about their performances and crave for more improvements if not maintaining their current performances. Rewarding employees helps to alleviate the doubts about their abilities. A good reward system will also, help in maintaining good behavior as the employees who receive praise will more likely continue to work 
hard and smart (Stone, 2002).

The main purpose of any form of reward is to motivate the workers because it helps to improve the morale of employees, fostering their work environment. They are satisfied with their jobs and will even try helping the others in their roles to ensure the completion of tasks. In cases of new employees, reward system, mostly recognition and assistance can help them fit into their new work places more easily. They will also, feel encouraged and confident about their new jobs. It is thus, clear that reward and incentive systems in any organization helps both the employers and the employees. Motivation and reward to employees by the administration of an institution is a secret to quality performance of staffs and sustainability of the businesses. Rewards and incentives given in a working environment have several benefits. Incentives and rewards take different forms like monetary forms in which money is given to employees. The money can be in the form of paid time off, profit sharing plans, bonuses, employees' stock options and cash awards (Stone 2002). Non-monetary incentives can take the form of flexible work hours and training opportunities for the employees. Other than those two, institutions can also reward employees in the form of recognitions, which also act as a mode of passing feedback to the employees. The human resource may also be rewarded by assistance in maintaining their balance between work and social life.

Human Resource departments have duties of new employee recruitment, training of new and existing employees, developing employees and rewarding activities of employees; therefore, it plays a significant role in establishing employee empowerment. It ensures a balanced relationship between organization activities and government policy as well as surrounding community wellbeing. The responsibilities of a Human Resource Manager have been changing with time within given institutions. Contrary to the recent past, a Human Resource manager has to work with the institution as a partner and not just as an employee. He or she has the role of shaping the leadership and culturewithin the organization as opposed toroutine administration essentials. They will be capable of launching better methods and procedures that will enable an improvement inmanagement, positively structure development activities necessary for leadership and initiate an improvement in employee engagement (Whitely, 2002).

The volunteered actions of an institution in line with ecological and social requirements of an institution are referred to as Corporate Social Responsibility (Hunnicutt, 2009). Institutions make and implement most of the decisions out of their own free will in order to contribute to the existence of a better working environment that considers employee empowerment. An organization may take a critical role in human resource social investment so that it facilitates a productive growth. Over the years, most institutions have started to promote and implement the requirements of Corporate Social responsibility in their key objectives because responsible and sustainable practices are the expectations of stakeholders. Other than employee empowerment, Corporate Social Responsibility is responsible for sustainable resource managementandclimate change.It acts as a promoter of the vision of an institution alongside accounting to the stakeholders, investors and shareholders.

When the aspects of Corporate Social Responsibility are taken into account, anorganization will benefit from having a good reputation, an improved financial performance, and increased level of productivity. In this case, the community receives products that are assured of quality and safety, voluntary programs and charitable contributions. Besides, the increased benefits from an integrated program obligated to facilitate environmental management, recyclability, greater use of renewable resources and an integrated environmental management program. In the current global business agenda, the concept of Corporate Social Responsibility is critical. Communication and ensuring transparency will aid in making an institution appear upright and thereby, improve the standards of output.

In any given institution, there exists a variety of working attitudes and cultures. Theyhave an influence onan individual's and team levels as well as on the general company performance. An individual is supposed to get a chance of creating a company and personal relationships. A major limitation in many organizations is putting their employees in mind in the way they think about the customers like in the case of higher education institutions; more focus is given to the students than the staff because the students pay fees. They tend to forget to think of ways of engaging the employees, who particularly act as their internal clients. A very limited number of organizations do care a lot about the measure of their workforce return (Topolosky, 2000). Employees should be handled in a similar way that external clients are treated. Engaging employees as if they are among the top clients of the organization is a psychological empowerment move, and it does a lot inboosting the labour power (Lea, 2012).

The personal needs of workers ought to be given more priority. Employee treatment implies the manner at which a manager or an employer relates to other workers. The treatment of employees should go hand in hand with respect to establishing a better work output. One of the responsibilities of managers is to always ensure that the employees' morale is high (Whiteley, 2002). A right combination of the management styles used by an employer or manager will result in a better employee treatment, and the end result will be an improved level of productivity. A responsible boss 
takes a considerable time to listen to the workers regarding matters of their needs and concernfor regular communicationand job performance. The employer should assign tasks that employees are either professionally or naturally good at. Also, the manager should facilitate further training when needed for the employees so that future frustrations are avoided when executing tasks that require particular skills. Hence, it is the role of the management to determine the motivating aspects that rejuvenate employee performance and tie their efforts to some sort of reward.

Top management ought to ensure a frequent communication either straight downwards or straight upwards in order to avoid misconception among the stakeholders. With regard to Corporate Social Responsibility, an institution should shift most of its focus on environmental protection rather than giving priority to compensating fouls that are committed against the community so that they are in line with the concept of 'prevention is better than cure.' A Human Resource manager ought to ensurea good planning of the employees' shifts to create time needed for a personal relationship. The managers should learn and understand the abilities of each of the employees and place them in a position in which they work best. Moreover, the managers should provide a working timetable which favours personal relationship building of the human resource.

\section{Conclusion}

Based on the explanations provided in the literature review, PE has an effect on OC. The four cognitions of PE that include impact cognition, self-determination cognition, competence cognition and meaning cognition affect OC. considering the data gathered and analysed using methods of statistical analysis, deductions can be made that there was a critical relationship between the studyvariables. Impact and self-determination do influence employees' commitment to aninstitutionwhereas it is partly supported by competence and meaning, which do not have an influence on the organizational commitment.The extant literature depicts that PEhas influences over three organizational commitment dimensions that are continuance commitment, normative commitment and affective commitment. Key sources of competitive advantage will not only focus on new technology but also on the competence of the workforce, dedication and the quality of the commitment.

Institutions are continuously upgrading their systems, processes, and technology to cope with challenging and a competitiveenvironment.Theresearch is useful in handling workers' attrition issues, loyalty at work and engagement initiatives. Findings of the research show that length of service and education level did not significantly provide a moderation in the relationship between $\mathrm{OC}$ and PE. Even though empowerment is an important management practice, not all institutions opt for it. With regard to an employee, they may seem reluctant to develop responsible decision as they may not want to take blames for the mistakes that may come up from theirdecisions.Another issue is trust because in most times the management does not trust the employees they lead because sharing information could imply leaking knowledge, ideas, and plans to rival institutions.Also on the manager's side, they fear losing authority, power, and control over their employees.

Each individual worker within an organization must bear a sense of belief that they have the neededcapabilities and skills to do their work in betterway.In case the objectives of the assigned task conflict with the employees' value systems, theworkerswill lack a feeling of empowerment.Managers should also not assign tasks that need high quality skills that surpass their employee's abilities.Besides, the managers should not delegate tasks that are extremely difficult to achieve and unattainable. That is because doing so mayresult in reduced commitment and motivation towards the institution (Dee, Henkin \& Duemer, 2002). Faculty members of universities should shift their educational pedagogy from "faculty cantered" to "student cantered" so that they engage the students in the entire process of education. Moreover, it is paramount to use various teaching strategies, whichensure objectives achievement and motive students. A possible reason that explains why impact and competence dimensions of PE do not significantly have an influence on the level of OC could be differences in cultures and should be studied in subsequent studies.

The study has a few setbacks. Theresearchentailed the use of a questionnaire based one institution anddependedentirely on the respondents' understanding. Therefore, the findings may not be generalized to any other higher education institution without taking caution.Further studies need to be conducted to investigate what factors moderate the relationship that exists between commitment and empowerment. Hopefully, this research will have a great contribution towards an ideal and better way of overall human resource management and organizational management.

\section{References}

Alamri, M. (2011). Higher education in Saudi Arabia. Journal of Higher Education Theory and Practice, 11(4), 88. 
Ambad, S. N. A., \& Bahron, A. (2012). Psychological empowerment: The influence on organizational commitment among employees in the construction sector. Journal of Global Business Management, 8(2), 73.

Bahron, A. (2006). Kesan Empowermen Psikologi Ke Atas Kepuasaan Kerja, Komitmen Organisasi Dan Kelakuan Kewargaan Organisasi. Disertasi Doktor Falsafah, Fakulti Ekonomi dan Perniagaan, Universiti Kebangsaan Malaysia.

Bogler, R., \& Somech, A. (2004). Influence of teacher empowerment on teachers' organizational commitment, professional commitment and organizational citizenship behavior in schools. Teaching and teacher education, 20(3), 277-289. https://doi.org/10.1016/j.tate.2004.02.003

Chan, Y. H. (2003). A nomological network approach to the study of antecedents, moderator, mediators and outcomes of psychological empowerment. Doctoral dissertation, University of Memphis, Memphis.

Choong, Y. O., Wong, K. L., \& Lau, T. C. (2011). Psychological empowerment and organizational commitment in the Malaysian private higher education institutions: A review and research agenda. Academic Research International, 1(3), 236.

Dewettinck, Koen, Jagdip Singh, and Dirk Buyens. (2003). Psychological empowerment in the workplace: Reviewing the empowerment effects on critical work outcomes. Vlerick Management School.

Hunnicutt, S. (2009).Corporate social responsibility. Detroit, MI: Greenhaven Press.

Janssen, O. (2004). The barrier effect of conflict with superiors in the relationship between employee empowerment and organizational commitment. Work \& Stress, 18(1), 56-65. https://doi.org/10.1080/02678370410001690466

Konczak, L. J., Stelly, D. J., \& Trusty, M. L. (2000). Defining and measuring empowering leader behaviors: Development of an upward feedback instrument. Educational and Psychological Measurement, 60(2), 301-313. https://doi.org/10.1177/00131640021970420

Lambert, S. J. (2000). Added benefits: The link between work-life benefits and organizational citizenship behavior. Academy of management Journal, 43(5), 801-815. https://doi.org/10.2307/1556411

Laschinger, H. K. S., Finegan, J. E., Shamian, J., \& Wilk, P. (2004). A longitudinal analysis of the impact of workplace empowerment on work satisfaction. Journal of Organizational Behavior, 25(4), 527-545. https://doi.org/10.1002/job.256

Lea, W. Inc. (2012).A Better Way to Treat Your Employees. Retrieved from http://www.inc.com/wendy-lea/treat-your-employees-like-humans-increase-productivity.html

Liden, R. C., Wayne, S. J., \& Sparrowe, R. T. (2000). An examination of the mediating role of psychological empowerment on the relations between the job, interpersonal relationships, and work outcomes. Journal of applied psychology, 85(3), 407. https://doi.org/10.1037/0021-9010.85.3.407

Menon, S. (2001). Employee empowerment: An integrative psychological approach. Applied Psychology, 50(1), 153-180. https://doi.org/10.1111/1464-0597.00052

Nabila, A. A. (2008). The relationship between Psychological Empowerment and organizational Commitment: A case study among employees in the construction sector in Kota Kinabalu, Sabah. School of Business and Economic, UMS (unpublished Masters dissertation).

Rawat, P. S. (2011). Effect of psychological empowerment on the commitment of employees: An empirical study. In 2nd International Conference on Humanities, Historical and Social Sciences, 17, 143-147.

Spreitzer, G. M. (2008). Taking stock: A review of more than twenty years of research on empowerment at work. Handbook of organizational behavior, 54-72. https://doi.org/10.4135/9781849200448.n4

Suliman, A. M. (2002). Is it really a mediating construct? The mediating role of organizational commitment in work climate-performance relationship. Journal of Management Development, 21(3), 170-183. https://doi.org/10.1108/02621710210420255

Topolosky, P. S. (2014). Linking employee satisfaction to business results. Routledge.

Whiteley, P., \& Seyd, P. (2002). High-intensity participation: the dynamics of party activism in Britain. University of Michigan Press. https://doi.org/10.3998/mpub.14704 